\title{
PARTICIPATIVE LEADERSHIP STYLE AND SUPPLY CHAIN PERFORMANCE OF RETAIL SMES IN RIVERS STATE OF NIGERIA
}

\author{
Olomi Progress Ovunda (PhD) ${ }^{1}$ and Ikegwuru Mac-Kingsley (PhD) ${ }^{2}$ \\ ${ }^{1}$ Department of Management, Rivers State University, Port Harcourt, Nigeria. \\ Email: progressolomi@gmail.com \\ ${ }^{2}$ Department of Marketing, Rivers State University, Port Harcourt, Nigeria. \\ Email: bestvaluecrest@gmail.com
}

\begin{abstract}
Cite this article:
Olomi P.O., Ikegwuru M.

(2021), Participative

Leadership Style and Supply

Chain Performance of Retail

SMEs in Rivers State of

Nigeria. British Journal of

Management and Marketing

Studies 4(2), 44-53. DOI:

10.52589/BJMMS/WSBN9Y

BB.
\end{abstract}

\section{Manuscript History \\ Received: 16 March 2021 \\ Accepted: 13 April 2021 \\ Published: 27 April 2021}

Copyright () 2020 The Author(s). This is an Open Access article distributed under the terms of Creative Commons Attribution-

NonCommercial-

NoDerivatives 4.0

International (CC BY-NC-ND

4.0 ), which permits anyone to

share, use, reproduce and redistribute in any medium, provided the original author and source are credited.
ABSTRACT: This study examined the effect of participative leadership style on supply chain performance of retail SMEs in Rivers State of Nigeria by means of a survey research design and quantitative method to tolerate descriptive and inferential analysis. The population for the study was 377 registered SMEs in Rivers State of Nigeria. The convenience simple technique was used to select one respondent each from the 377 retail SMEs studied. The convenience sampling of respondents was used to 377 respondents for the study. Afterward, 377 copies of questionnaire were disseminated to 377 employees across the identified retail SMEs. Of the 377 respondents contacted, 258 participated in the study; ensuing to a response rate of 68 The 258 respondents produced a total of 249 functional response set. Data were espoused to correlation and regression analysis by means of the statistical package for social sciences (SPSS Version 22.0). It was revealed that, participative leadership style statistically positive and influence information sharing at 0.05 significant level. This implies that a well implemented participative leadership style can increase the chance of making better information sharing in retail supply chain. The study therefore, concludes that, there is a positive and significant influence of participative leadership style on supply chain performance of retail SMEs in Rivers State of Nigeria, and recommends that managers of retail SMEs should emphasis more on the implementation of participative leadership style in their organizations to boost information sharing in order to attain superior supply chain performance.

KEYWORDS: Information Sharing, Participative Leadership Style, Retail SMEs, Supply Chain Performance 


\section{INTRODUCTION}

In today's disordered, shifting and swiftly dynamic environment, an adjustment of the relationship between managers and workers, and a possible adoption of a leadership style that is anchored on teamwork, participation, and involvement of workers in decision making and the analytical process is highly imperative. This is because; the behavior of employees in organizational life and their relationship with their jobs is affected by leadership behavior. It clear as crystal, that leadership behavioural styles have significant allusions for workers and companies as posited by through an assortment of scholarly studies. For instance, firms are currently surfacing en route for arrangements in which status connotes accountability other than power, as well as where the superior's post is not to command, save for to convince (Hesselbein \& Cohen, 1999).

A leadership behavioural style such as participative leadership style gives prospects to workers to share their resourceful thoughts to recover a serious state of affairs (Lamb, 2014). A participative leader motivates supporters and encourages them to partake in decision making to achieve organizational objectives. Managers are therefore, required to influence their subordinates, peers, and superiors to support and sustain their suggestions, plans, and to encourage them to implement their resolutions, in order to be successful (Blickle, 2003). Several scholars have actually identified that their concern in leadership with special reference to different organizational outcomes possibly will be accredited to the prevalent credence that leadership has an instant influence on performance (Rowe et al., 2005).

Several studies have been hoisted to disentangle the association between participative leadership style and performance (Misbah, et al., 2019; Dyczkowska \& Dyczkowski, 2018; Newman, Phillip \& Teo, 2012; Nemaei, 2012). Nonetheless, there is a deficiency of a distinct, applicable and prearranged study that put in plain words the application of participative leadership style in SMEs over the years. Therefore, there exists a significant research gap, and the need to understand how the participative leadership style will work towards improvement in the supply chain performance of retail SMEs for future research in contemporary times gives rise to the need of structuring this investigation. Thus, the purpose of this research paper is to depict a clear picture of the effect of participative leadership style on supply chain performance of retail SMEs in Rivers State of Nigeria and explore innovative areas of investigation that would help researchers and scholars in hypothesizing novel investigative possibilities for research and development in the realm of organizational leadership style and supply chain performance. This progress in the discipline will lend a hand to stakeholders to take sound resolutions, backed by a methodical literature and empirical pedestal.

\section{Statement of the Problem}

Retail small and medium enterprises (SMEs) are involved in processes adopted to move products to final consumers. It takes in everything in their supply chain, from obtaining the raw materials to making product to delivering that product into consumers' hands.

Retail SMEs therefore, optimize those processes to maximize both speed and efficiency to be as reasonably priced as they can cope, and deliver products into a consumer's hands as fast as they can. Conversely, they don't desire to pay contemptible amounts to do that. They optimize their processes to be as efficient and reasonably priced as they can cope. However, 
the applicable question that materializes here is: Does the adoption of participative leadership style relate with information sharing in retail SMEs supply chain in Rivers State? In this paper, the study focused on information sharing, a component of supply chain management, and investigates how it can be predicted by participative leadership style in small and medium sized enterprises (SMEs) in Rivers State of Nigeria.

\section{Research Question}

Does the adoption of participative leadership style relate with information sharing in retail SMEs supply chain in Rivers State?

\section{LITERATURE REVIEW AND HYPOTHESES}

\section{Theoretical Underpinning}

\section{Trait Theory}

The trait standpoint was one of the original theories of leadership in the 1940's which presupposes that great leaders are born with eminent individuality traits that make them wellmatched for leadership and make them special from other people or their cohorts. Stogdill (1948) who created the most all-inclusive listing of traits observed that leadership circumstances differ considerably and place diverse claims on leaders, destroyed trait theory, leading to the emergence of situational and behavioral approaches.

This study suggests that a successful leader must accede to definite quality that brings prominence into being (Northouse, 2007). This theory imagined that leaders are cleverer than followers, able to kick off take actions autonomously with high administrative aptitude, more imaginative, possess elevated levels of flexibility and attentiveness and self-assurance. A lot of personality traits, social traits and physical uniqueness can differentiate leaders from followers (Rue \& Byars, 2007). Investigations of the affiliation between effective leadership and physical uniqueness as height, weight and appearance offer conflicting outcomes ((Ivancevich et al., 2008). However, scholars acknowledged that traits were not adequate alone to classify effective leaders and the exchanges between leaders and their followers had been overlooked (Robins \& Coulter, 2009).

\section{Participative Leadership Style}

Participative leadership is a significant leadership behaviour that was long-established by assorted scholars to have a strong connection with employee performance (Dalluay \& Jalagat, 2016, ISPAS, 2012, Iqbal, Anwar \& Haider, 2015, Mulki, Caemerer \& Heggde, 2015). Participative leadership was discovered to have significant influence on job satisfaction and productivity of employees (Dalluay \& Jalagat, 2016). It was also discovered that participative leadership style positively and significantly influences employee performance in long term (Iqbal et al., 2015). Participative leaders are enable to boost employee endeavors leading to healthier employee job performance (Mulki et al., 2015). Benoliel and Somech (2014) found that participative leadership style has a positively relationship with employee performance. Newman et al. (2014) noted that the influence of participative leadership style on employee job performance is a function of the level of trust. Kim and Schachter (2015) revealed that a 
strong relationship exists between followers and participative which subsequently leads to tall employee job performance (Kim \& Schachter, 2015). However, studies such as Hwang et al. (2015) give an idea that participative leadership style does not have any significant relationship with job performance, but in disparity, Yang and Lim (2016) found a positive influence of participative leadership style on job satisfaction. Therefore, the adoption of participative leadership style allows all and sundry to have a voice in making the final decision, which has bearing with the mainstream of workers. Since the leader relocates the power to the followers, this leadership style can be said to increase the level of performance in organizations.

\section{Supply Chain Performance}

The word Performance is more often than not used to clarify assorted facets such as performance of business, performance of employees and performance of person. Maestrini, Luzzini, Maccarrone and Caniato (2017) defined performance as "A set of metrics used to quantify the efficiency and effectiveness of supply chain processes and relationships, spanning multiple organizational functions and multiple firms and enabling supply chain orchestration". Campbell, McCloy, Oppler and Sager (1993), confirmed two measurements of performance; as behavioral part and outcome performance part. Kauppi et al. (2016) measured supply chain performance by operational performance by means of indicators such as quality performance, flexibility performance, customer service, delivery performance and cost performance, Effendi (2015) used logistic effect and indicators as order fill rate, order fulfillment lead time, operations flexibility, inventory turnover, and total logistics cost. This study in line with Flynn et al. (2010)) adopts information sharing and as the measure of supply chain performance.

\section{Information Sharing}

This presages the aggregation of communication or intelligence stream to intersect or pass through the supply chain. It enhances desirable or satisfactory execution of actions. Information sharing advances the chances of survival in operations and moves forward an effective supply chain (Xu, 2012; Yan, 2014). Information shared in supply chain requires the presence of inherent features that imbibes confidence, well-timed, having a clear meaning, and conforming exactly to truth or to a standard (Chan \& Chan, 2010).

The credence of sharing comprehensive communication or intelligence through the supply chain for firms is extensively premeditated (Liu, Shah \& Setiroeder, 2012; DeGroote \& Mars, 2015; Wang, $\mathrm{Hu} \& \mathrm{Hu}, 2013)$. The ability to engender competitive advantage (Xu, 2012), in the midst of sustainable reciprocated understanding is inbuilt in supply chains who value the quintessence of competitive advantage in their company (Sivestro \& Lustrato, 2014). Mutual understanding in relationship is impracticable in a state of affairs where members hold unable to get along interests ((Yan, 2014). Thus, the credibility of information sharing in the supply chain for firms is interminably calculated. 


\section{Empirical Review}

Misbah et al. (2019) examined the mediating role of affective and cognitive trust, and the moderating role of continuous commitment on participative leadership and organizational citizenship behavior (relationships by means of four hundred employees in hotel industry in Pakistan. The bootstrapping method was adopted for an evaluation of the mediation effect by the process macro. The study adopted the confirmatory factor analysis and structural equation modeling for data analysis. It was found that affective trust significantly moderate the relationship between participative leadership and organizational citizenship behavior. Furthermore, continuous commitment significantly moderates the relationship between participative leadership and organizational citizenship behavior.

Dyczkowska and Dyczkowski (2018) studied the relationship between participative management and rewarding strategies as well as employees' job satisfaction in SME in Polish enterprises. The study used data from 93 SMEs and 86 large companies, collected at the twist of 2013 and 2014. The study demonstrates that involvement of employees in managerial affairs affects performance-based rewarding strategies, and that such involvement spurs employees' job satisfaction.

Newman et al. (2012) considered the relationship between participative leadership style and job performance contained by the internship site in South-East of China. Using two-wave survey data acquired from 309 interns and their supervisors, confirmatory factor analysis (CFA) and structural equation modeling (SEM) was carried out by means of LISREL 8.80 to test the study's hypotheses. The result reveals that participative leadership style has a positive relationship with job performance and that affective trust moderates the relationship between participative leadership style and job performance. The study also discovered that cognitive trust is not significantly related to intern job performance, but it moderates the relationship between participative leadership and affective trust.

Nemaei (2012) study was to identify obtainable problems with transformational leadership style and strive to attend to these problems by means of participative leadership style. The study adopted a comparative research method and carried out an action research-based study on a small group of employees. Data collection for the study was conducted with structured interview. The study revealed that the level of employee's motivation, job satisfaction and innovation is higher when participative leadership style is implemented. Therefore, participative leadership style is better than transformational leadership style all things being equal.

Based on the review of literature, the following conceptual framework was constructed: 


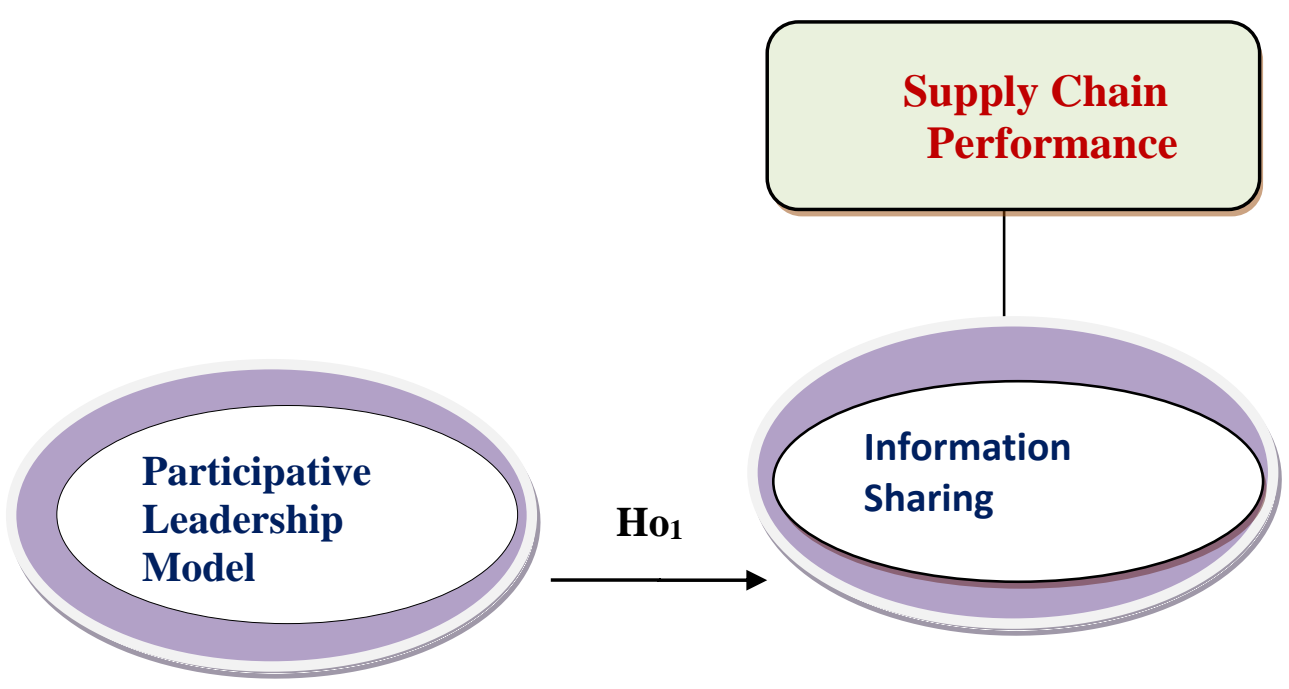

Figure 1: Operational Framework of Participative Leadership Style and Supply Chain Performance.

Sources: Adopted from Schoenherr and Swink (2012).

Flynn, Huo and Zhao (2010).

Based on the review above, the following hypothesis was raised:

Ho1: Participative leadership style does not significantly influence information sharing of retail SMEs in Rivers State of Nigeria.

\section{RESEARCH METHODOLOGY}

The study espoused a survey research design and quantitative method to tolerate descriptive and inferential analysis. The study adopted a cross-sectional investigation on all the SMEs registered with the Rivers State Chamber of Commerce and Industry, Port Harcourt, numbering just about 2000 SMEs as at January, 2021. The sample size for this study was obtained from the instruction built up by Krejcie and Morgan (1970) on the resolving the issue of sample size from a specified population. The study has a minimum sample size of 377. The convenience sampling technique was used to select employees present at their place of work as respondents for the study. Afterward, 377 copies of questionnaire were disseminated to 377 employees across the recognized retail SMEs. Of the 377 respondents made contact with, 258 participated in the study, ensuing a response rate of 68 percent and it has been entrenched in literature that a response rate above 30 percent is an outstanding and permissible point when the study takes up survey questionnaire (Moser \& Kalton, 1971). The 258 respondents generated a total of 249 functioning response set. Data were analyzed with correlation and regression analysis by means of the statistical package for social sciences (SPSS Version 22.0). 


\section{RESULTS}

\section{Research Question One:}

The relationship between participative leadership style and information sharing of retail SMEs. Correlation analysis in Table 1 presents the results of bivariate correlation based on Pearson correlation statistics.

Table 1: Relationship between Participative Leadership Style and Information Sharing $(\mathrm{N}=\mathbf{2 4 9})$.

Sharing

Participative Leadership Style Information

Participative Leadership Style

Sig. (2-tailed)

$\mathrm{N}$

Information

Sharing
Pearson's correlation Sig. (2-tailed)

$\mathrm{N}$
1

249

.754

.0000

249
.754

.0000

249

1

249

** Correlation is significant at 0.01 level (2-tailed).

Table 1 shows that ssupportive leadership model exhibited positive and significant with supply chain performance. $\mathrm{r}=0.685$ implying there is a strong positive correlation.

\section{Simple Regression Analysis}

The simple regression analysis was carried out to estimate the effect of supportive leadership style (independent variables) on information sharing (dependent variable). Results are presented in Tables 2.

Table 2 Model Summary

Model R R Square Adjusted R Std. Error of Change Statistic Square the Estimate F Change Sig. F Chang

Durbin Watson

\begin{tabular}{llllllll}
1 & .754 & .674 & .671 & 294.95 & 62.3027 & 0.000 & 1.827 \\
\hline
\end{tabular}

a. a. Predictors: (Constant), Participative Leadership Style,

b. Dependent Variable: Information Sharing

Source: SPSS Window Output (based on 2021 field survey data). 
Table 2 presents a summary of the model in which the item of interest is the adjusted R2 statistics, which is .671. This suggests participative leadership model accounts for $67.1 \%$ of the variation in information sharing. The adjusted R-square is used to test the overestimation of $\mathrm{R}$ square. The estimates show an error of 0.62035 , which cannot be considered as very large. The Durbin - Watson statistic $d=1.827$ lies between the two critical values of $1.5<\mathrm{d}$ $<2.5$, and therefore it can be assumed that there is no first order linear autocorrelation data of simple linear regression model. Hence, it can be concluded that the overall model is statistically significant, or that the variable have a significant effect on the dependent variable. The participative leadership variable exact significant influence on information sharing since the significant value (or p-value) is .000 which is below the 0.05 level of significance. Table 3 shows the model fit results.

Table 3 Model Fit Results

ANOVA ${ }^{\mathrm{a}}$

\begin{tabular}{|ll|r|r|r|r|r|}
\hline \multicolumn{2}{|l|}{ Model } & \multicolumn{1}{|c|}{$\begin{array}{c}\text { Sum of } \\
\text { Squares }\end{array}$} & Df & $\begin{array}{c}\text { Mean } \\
\text { Square }\end{array}$ & F & Sig. \\
\hline 1 & Regression & 874.298 & 1 & 874.298 & I367.375 & $.000^{\mathrm{b}}$ \\
& Residual & 167.674 & 248 & 758 & & \\
& Total & 1041.972 & 249 & & & \\
\hline
\end{tabular}

a. Dependent Variable: Information Sharing

b. Predictors: (Constant), Participative Leadership Style

Table 3 presents the analysis of variance (ANOVA) results. It is also known as model fit results. Of interest in this table are the F-statistics and its associated sig. value. The results show that the F-statistics is $1.539 \%$ ( $\mathrm{p}<0.01$ ). The results point out that the model's hypothesis that the "model has no power to predict information sharing from participative leadership style scores" could not be accepted. Therefore, the model has power to predict information sharing significantly from the participative leadership style scores.

Table 4. Regression Coefficients

Table 4: Coefficients of Infrastructure Adoption and Information.

\begin{tabular}{|llclll|}
\hline & \multicolumn{4}{l|}{ Unstandardized Coefficients } & \multicolumn{4}{l|}{ Standardized Coefficients } \\
\hline Model & $\mathrm{B}$ & Std. error & Beta & T & Sig. \\
Constant & 8.411 & .639 & & 2.197 & .000 \\
& .627 & .559 & .754 & 7.171 & .000 \\
PLS & &
\end{tabular}

a. Dependent Variable: Participative Leadership Style

Source: SPSS Window Output (based on 2021 field survey data). 
Table 4 presents the results on the coefficients of the regression model. The coefficients results show that participative leadership style positively predicts information sharing, standardized $\mathrm{B}=.627,(\mathrm{p}<0.01)$. This result suggests that information sharing of retail SMEs whose direct superior show signs of participative leadership distinctiveness increased significantly by 62.7 percent.

\section{DISCUSSION OF THE RESULTS}

In a summation, the regression analysis spells out that, participative leadership style positively predicted information sharing. If managers show signs of added supportive leadership, retail SMEs will have higher information sharing performance. Thus, retail SMEs managers should be profusely insightful and become conscious that their alignment with workers are very important in enhancing information sharing in their organizations. As predicted, this result does not support hypothesis 1, that participative leadership style does not significantly influence information sharing of retail SMEs in Rivers State of Nigeria. The alternative hypothesis that participative leadership style significantly influence information sharing of retail SMEs in Rivers State of Nigeria was therefore accepted. The results of participative leadership model are in line with those of Dyczkowska and Dyczkowski (2018) who fund that involvement of employees in managerial affairs affects performance-based rewarding strategies, and that such involvement spurs employees' job satisfaction, Newman et al. (2012) (2013) who made known that participative leadership style has a positive relationship with job performance and that affective trust moderates the relationship between participative leadership style and job performance, and Nemaei (2012) who unveiled that the level of employee's motivation, job satisfaction and innovation is higher when participative leadership style is implemented.

\section{CONCLUSION AND RECOMMENDATIONS}

The study investigated the influence of participative leadership style on supply chain performance of retain SMEs in Rivers State of Nigeria. The study revealed that retail SMEs managers who implement participative leadership style in their companies have better performance in their information sharing activities. The study therefore concludes that, participative leadership model significantly influences supply chain performance of retail supply chain in Rivers State of Nigeria. The study recommends that managers of retail SMEs should emphasis more on the implementation of participative leadership style in their organizations to boost information sharing in order to attain superior supply chain performance.

\section{REFERENCES}

Campbell, J. P., McCloy, R. A., Oppler, S. H. \& Sagar, C. E. (1993). A Theory of Performance. In N. Schmitt, W. C. Borman, and associates (Eds.), Personnel selection in organization: 35-69. San Francisco: Jossey-Bass. 
Dyczkowska , J. \& Tomasz Dyczkowski, T. (2018). Democratic or autocratic leadership style? Participative management and its links to rewarding strategies and job satisfaction in SMEs. Athens Journal of Business and Economics, 193-217.

Effendi, F.S.R. (2015).The Determinants of logistics efficiency in Malaysia. Social Science Research Network. Retrieed from www.google.com Accessed on October 14, 2020.

Flynn, B. B., Huo, B. \& Zhao, X. (2010). The impact of supply chain integration on performance: A contingency and configuration approach. Journal of Operations Management, 28 (1-2), 58-71,

Iqbal, N., Anwar, S. \& Haider, N., (2015). Effect of Leadership Style on Employee Performance. Arabian Journal of Business and Management Review, 5, 146.

Kauppi, K., Longoni, A., Caniato, F. \& Kuula, M. (2016). Managing country disruption risks and improving operational performance: Risk management along integrated supply chains. International Journal of Production Economics, 182, 484-495.

Krejcie, R.V. \& Morgan, D.W. (1970). Determining sample size for research activities. Educational and Psychological Measurement, 30, 607-610.

Lamb, R. (2014). How can managers use participative leadership effectively? Retrieved 14 October, 2020 from www.google.com.

Liu, G., Shah, R. \& Schroeder, R.G. (2012). The relationships among functional integration mass customization, and firm performance. Integration, mass firm performance. International Journal of Production $\quad$ Research, 50 (3), 677690.

Maestrini, V., Luzzini, D., Maccarrone, P. \& Caniato, F. (2017). Supply Chain Performance Measurement Systems: A Systematic Review and Research Agenda. International Journal of Production Economics, 183, 299-315

Misbah, H. B., Yanbin, J., Umair, A., Muhammad, H. B., Zubair, A. \& Muhammad, B. (2019). Impact of participative leadership on organizational citizenship behavior: Mediating role of trust and moderating role of continuance commitment: Evidence from the Pakistan hotel industry. Sustainability, 11, (1170), 1-21.

Moser, C. \& Kalton, G. (1971). Survey Methods in Social Investigation, (2nd ed.,) Educational Books, Heinemann.

Nemaei, B. (2012). The impact of participative leadership on employee's motivation, job satisfaction and innovation. MSc Dissertation. Faculty of Business. The British University in Dubai.

Newman, A., Phillip, R. \&.Teo, S.T.T, (2012). The role of participative leadership and trustbased mechanisms in eliciting intern performance: Evidence from China. ANZAM, 1-20.

Northouse, P.G, (2007). Leadership: Theory and practice. London. Sage publications.

Opoku, M.; Choi, S. Kang, S. (2019). Servant leadership and innovative behaviour: An empirical analysis of Ghana's manufacturing sector. Sustainability 2019, 11, 6273.

Robbins, S. P. \& Coulter, M. (2009). Management (10thed.). Pearson Prentice Hall.

Stogdill, R. M. (1974). Handbook of leadership. New York, Free Press.

Wang, E.., Hu, H. \& Hu, P. (2013). Examining the role of information technology in cultivating firms' dynamic marketing capabilities. Information and Management, $\quad 50$ (6), 336-343.

Yan, J., Xin, S., Liu, Q., Xu, W., Yang, L., Fan, L., Chen, B. \& Wang, Q. (2014). Intelligent supply chain Integration and management based on cloud of things. International Journal of Distributed Sensor Networks. 1-15. 